See Article page 62.

\section{Commentary: How we enter the chest in cardiac surgery - Does it really matter for the purpose of early extubation?}

\author{
Stefano Schena, MD, PhD
}

Rapid weaning from anesthesia and extubation in the operative room after cardiac surgery is living a new renaissance. Times have greatly changed since its first introduction, ${ }^{1}$ and the current relentless search for quality metrics or the widespread popularity of enhanced recovery after cardiac surgery protocols ${ }^{2}$ may present newer incentives. Inherent reluctance is still encountered, however, particularly among intensive care providers. The perception is to receive a patient possibly prone to respiratory complications who now will have to be rapidly addressed in the intensive care unit, ${ }^{3}$ or the suggested lack of clinical advantage in terms of early extubation, unless the timing exceeds 12 hours. $^{4}$

Although the practice of cardiac anesthesia has evolved remarkably, some prerequisites cannot be ignored. To achieve excellent outcomes, programs adopting extubation in the operating room must count on highly experienced surgeons and anesthesiologists, a staff with a common mission, inclusion of local and regional analgesic techniques and, last but not least, proper patient selection. ${ }^{5}$

In a recent article, Huang and colleagues ${ }^{6}$ have thrown a new variable into the mix. Huang and colleagues ${ }^{6}$ assessed the impact of the surgical incision (sternotomy vs minimally invasive approaches) on length of hospital stay among those cardiac surgical patients extubated in the operating room. The myth of the traditional, yet still most reliable, cardiac surgery incision going against thoracoscopic ports, robotic cameras, percutaneous access,

From the Division of Cardiac Surgery, The Johns Hopkins Hospital, Baltimore, Md. Disclosures: Author has nothing to disclose with regard to commercial support.

Received for publication Dec 4, 2019; revisions received Dec 4, 2019; accepted for publication Dec 12, 2019; available ahead of print Feb 4, 2020.

Address for reprints: Stefano Schena, MD, PhD, Division of Cardiac Surgery, The

Johns Hopkins Hospital, 1800 Orleans St, Zayed 7107, Baltimore, MD 21287

(E-mail: sschena1@jhmi.edu).

JTCVS Techniques 2020;1:65-6

2666-2507

Copyright (C) 2020 The Author(s). Published by Elsevier Inc. on behalf of The American Association for Thoracic Surgery. This is an open access article under the CC BY-NC-ND license (http://creativecommons.org/licenses/by-nc-nd/4.0/).

https://doi.org/10.1016/j.xjtc.2019.12.002

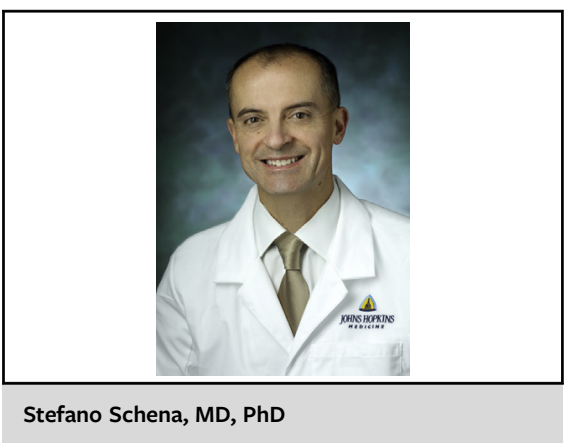

CENTRAL MESSAGE

Patients undergoing cardiac surgery through either sternotomy or less invasive incisions do not have any difference in hospital stay with an appropriate plan favoring extubation in the operating room.

and so on is again challenged. Huang and colleagues ${ }^{6}$ retrospectively compared 104 patients who underwent different operations and were subsequently extubated before leaving the operating room. Not unexpectedly, the group who received less invasive incisions included patients who had mostly valve operations and less complex procedures. Despite the relatively small patient sample, they concluded that patients undergoing a standard sternotomy would spend a similar amount of time (23 vs 20.6 hours) in the intensive care unit and an additional day in the hospital (4 vs 5 days). Operative and anesthesia times also did not differ.

The question then is whether size and location of entry really matter for the purpose of fast ("ultrafast" actually) tracking a cardiac surgical patient. In the absence of (unlikely) prospective, randomized trials, the answer seems to be negative. On the other hand, attempting to assess the role of a surgical incision and its effect on hospital stay may still be difficult if the incision only represents the entry for very different operations and does not take into account elements strictly inherent to each case's complexity. Two critical factors remain, in my opinion, judgment and communication. Although there is no substitute for appropriate patient selection, evaluation of individual circumstances and awareness of available resources, as well as embracing partnership with our colleague anesthesiologists, will lead us to benefit from the demonstrated advantages of 
early extubation. In the not so distant transcatheter universe, similar achievements (ie, minimalistic approach in transcatheter aortic valve replacement) occurred quite some time ago. For the more traditional open surgery, the knowhow is widely available. Future studies, however, will be critical to solve the timing conundrum regarding extubation and to exploit that for better resource use.

\section{References}

1. Cheng DC, Karski J, Peniston C, Raveendran G, Asokumar B, Carroll J, et al. Early tracheal extubation after coronary artery bypass graft surgery reduces costs and improves resource use. A prospective, randomized, controlled trial. Anesthe siology. 1996;85:1300-10.
2. Grant MC, Isada T, Ruzankin P, Whitman G, Lawton JS, Dodd-o J, et al; Johns Hopkins Enhanced Recovery Program for the Cardiac Surgery Working Group. Results from an enhanced recovery program for cardiac surgery. J Thorac Cardiovasc Surg. June 7, 2019 [Epub ahead of print].

3. Grawe E, Wojciechowski PJ, Hurford WE. Balancing early extubation and rates of reintubation in cardiac surgical patients: where does the fulcrum lie? J Cardiothorac Vasc Anesth. 2015;29:549-50.

4. Crawford TC, Magruder JT, Grimm JC, Sciortino C, Conte JV, Kim BS, et al. Early extubation: a proposed metric. Semin Thorac Cardiovasc Surg. 2016;28: 290-9.

5. Hemmerling TM. Immediate extubation after cardiac surgery should be part of routine anesthesia practice for selected patients. Ann Card Anesth. 2018;21: 114-5.

6. Huang Y, Wittner ED, Dearani J, Schaff HV. The impact of surgical incision on hospital stay in patients extubated in the operating room after cardiac surgery. J Thorac Cardiovasc Surg Tech. 2020;1:62-4. 